NOTE: This is the accepted version of a manuscript accepted for publication on January 25, 2017 by Sage Publishing's "Sociological Perspectives" journal.

\title{
Give Me Your Tired, Your Poor? Support for Social Citizenship Rights in the United States and Europe
}

\begin{abstract}
This article investigates whether the commitment to social rights as integral to a wellfunctioning democracy exists among Americans in comparison to their European counterparts. In our comparison of data from the European Social Survey (2012) with a special parallel module of the US Cooperative Congressional Election Survey (2014) the findings suggest that similar conceptions of ideal democracy are found on both sides of the Atlantic. Although Americans are less likely than Europeans to consider fighting poverty and reducing income inequality as important democratic ideals, the analysis shows that the US is not exceptional in the existence of a social rights conception of democracy. A distinct feature of US public opinion is that support for social rights is more strongly associated with a left-right divide than in Europe. The observed congruence between policy and public opinion in the US highlights the importance of investigating the direction of causality between both phenomena.
\end{abstract}

Keywords: political citizenship; social citizenship; latent class analysis; T.H. Marshall; European Social Survey; Cooperative Congressional Election Study; market citizenship

\section{Biographical notes:}

Jennifer Oser (oser@ post.bgu.ac.il ) is an assistant professor of Politics and Government at Ben-Gurion University (Israel), and conducted research on inequality and political participation as a visiting scholar at Harvard University and the University of Pennsylvania. She has published mainly on topics of political behavior and public policy.

Marc Hooghe (marc.hooghe@ soc.kuleuven.be) is a full professor of political science at the University of Leuven (Belgium). He has published mainly on participation and political attitudes, and he holds an ERC Advanced Grant to investigate the democratic linkage between citizens and the state.

\section{Acknowledgment:}

The authors wish to thank the European Research Council for the ERC Advanced Grant 295920 on democratic linkage between citizens and the state 


\section{Introduction}

Across industrialized societies, the extent of social welfare provisions varies widely. Various typologies have been suggested to introduce a distinction between different types of welfare regimes, such as Esping-Andersen's (1990) well-known but also contested distinction between liberal, corporatist-statist and social-democratic welfare states. These types differ not only in their scope and the effectiveness of welfare coverage, but also with regard to the institutions and organizations that are responsible for administering welfare state provisions (Scruggs \& Allan, 2006). In this literature, the United States stands out among other highly industrialized countries as a prime example of a liberal welfare state. Partly as a result of the absence of leftist political parties, social expenditure levels remain low compared to other industrialized societies (Hicks \& Swank, 1992).

Data from the OECD (2016) show that public social expenditure in the United States amounts to $19.3 \%$ of GDP, which is remarkably lower than Germany (25.3\%), Japan (23.1\%), or the United Kingdom $(21.5 \%)$. With regard to the level of public social expenditure that is strictly comparable across countries, the United States clearly is in the lower half of the OECD rankings (OECD, 2016), even as a number of specific US government policies that contribute to social welfare have been aptly termed "invisible" (Mettler, 2011). The political debate on the Affordable Care Act also suggests that expanding social protection programs is a difficult endeavor in contemporary US politics (Corman \& Levin, 2016; Jacobs \& Skocpol, 2015; Obama, 2016). This kind of cross-national comparison inevitably raises the question of how to explain the reluctance of the US political system to develop a more comprehensive social security system as exists in other major OECD economies. While we know that there is a phenomenon of American exceptionalism with regard to social policy (Teles, 1998), the main question in this article is to assess whether there is also a form of exceptionalism as far as public opinion on this topic is concerned. In this paper our goal is to investigate whether the relatively modest investment in social protection programs in the US coincides with American public opinion preferences in comparison to other highly industrialized democracies.

There are sharp differences between countries with regard to public opinion on social policy and redistribution, and some research suggests that the United States has a 
distinct position compared to other Western democracies (Alesina \& Angeletos 2005; Alesina \& Glaeser, 2004; Jæger, 2009). Opinions differ, however, on the causal logic used to explain these differences and two different lines of research can be distinguished in this regard. On the one hand, research has shown that that government policy responds to preferences within public opinion, although the degree of responsiveness can show significant differences depending on the characteristics of the political system (Kang \& Powell 2010). If public opinion is not supportive of redistribution efforts, the political system does not receive sufficient incentives to develop a strong redistribution scheme (Hicks \& Swank, 1992). Following this logic, the study of public opinion is relevant, because it helps us to explain why the United States spends less on redistribution efforts than other highly industrialized democracies. On the other hand, however, it has also been argued that public opinion reacts to the functioning of the system: once a specific system has been implemented based on specific historical circumstances, public opinion will take this system for granted and internalize its norms and expectations. This impact of national contextual factors is evident in research on welfare regime type as a possible determinant for varying support for social policies (Jæger 2009). In this literature that has been labelled as the "welfare regime hypothesis", public opinion is seen mainly as a result of historically developed policy arrangements. In any case, both lines of the literature lead to the expectation that there will be a positive relationship between government policy and public opinion preferences, regardless of the direction of causality. No matter what theoretical option is being pursued, therefore, it remains highly relevant to assess the support within public opinion for redistribution policies.

To investigate the structure of public opinion beliefs regarding social welfare provisions, we rely on the theoretical framework developed by T.H. Marshall (1950). The expansion of the welfare state is not only a matter of policy measures, according to Marshall, but also reflects an important phase in the expansion of democratic rights. In Marshall's view, prior to the $20^{\text {th }}$ century democratic systems implemented civil and political rights, while during the $20^{\text {th }}$ century democracy increasingly came to be defined as an expansion of social rights, meaning the right of all citizens to enjoy decent living conditions, and the establishment of a social security system that aims to guarantee these conditions. A lower level of support among US citizens for social rights as part of a comprehensive democratic ideal might therefore be one of the reasons why 
the United States has developed a more restrictive social security system (Garfinkel, Rainwater \& Smeeding, 2010). This hypothesis will be tested by analyzing recent public opinion data on democratic ideals which allow for a direct test of the T.H. Marshall theoretical framework. The data also allow for a comparison between the US and European societies, so that it can be investigated whether there is a degree of American exceptionalism regarding support for social rights. The use of the same questions on both sides of the Atlantic allows us to assess to what extent Europeans and Americans differ on the importance they attach to the granting of social rights.

In this paper, we first offer a brief review of the literature, before presenting data and methods. Following the results section, we close with some observation on what these findings imply for social policy in the United States.

\section{Social rights and citizenship}

T.H. Marshall distinguished three different conceptions of citizenship in the historical development of modern democracy. Civil citizenship corresponds to the entitlement to basic rights, like freedom of speech, thought and faith and the right to own property. While some of these rights date back to the Magna Carta (1215), Marshall himself considered their proliferation and generalization mainly as an $18^{\text {th }}$ century phenomenon. Political citizenship implies the right to vote for office-holders, or to be a candidate oneself for elected positions of power. Social citizenship, finally, was defined as the right "to live the life of a civilized being according to the standards prevailing in the society. The institutions most closely connect with it are the educational system and the social services" (Marshall 1964, 72).

The main innovation in Marshall's approach was not his sketch of this historical development, but rather the fact that he considered these three conceptions of citizenship as elements of the same process of broadening fundamental democratic rights. From Marshall's perspective, once citizens are recognized as full members of society, they also receive undeniable social rights, such as protection against poverty. In other words, social rights have become an integral element of the status of citizenship in the $20^{\text {th }}$ century (Marshall 1964, 96). Despite a tendency to give more priority to one set of values compared to another (Ariely 2011, 243), it is clear that in Marshall's view, 
there is no trade-off relation between political and social rights, as both sets of rights must be ensured simultaneously (Revi, 2014). As such, Marshall's writings helped to legitimize the historically unprecedented expansion of the social protection function of the state, most notably in the United Kingdom. In the normative literature, this development is not considered an incremental expansion of the scope of government intervention, but rather is viewed as a structural transformation of the way contemporary democracy is conceptualized (Cox, 1998). Marshall's theory of citizenship has had a strong impact on normative political science, predominantly due to his placement of social rights at the heart of conceptualizing democracy and citizenship. While this insight has influenced the normative debate on social policy, the distinction between political and social citizenship is rarely used in empirical political science (Bulmer \& Rees, 1996). Therefore, we do not know whether this theoretical concept actually resonates in public opinion, and, if so, whether it could offer an explanation for how citizens envision policy issues of redistribution and social security.

Marshall's theory of citizenship relates to contemporary comprehensive welfare state arrangements that became considered a means to ensure the use of full citizenship rights (Korpi, 1989). The distinction introduced by Marshall became a mobilizing concept that reframed social policy as integral to the realization of citizens' basic rights and no longer as an ideological preference (Connell, 2012). Nevertheless, in the literature, the contemporary relevance of Marshall's ideas has also been challenged. More specifically, it is assumed that because of the growing hegemony of economic considerations, the identification of citizenship as a purely political category has been eroded. Increasingly, the distinction between citizens and consumers is being blurred as citizens are considered as consumers of government services. Deckard and Heslin (2016) even claim that this process has led to the development of what they label as market citizenship. This trend implies that citizens are no longer considered as human beings that are invested with rights (Somers, 2008). Citizens are instead considered a form of market commodity that no longer carries inalienable rights, but is interchangeable on various market-driven exchange mechanisms. If this commodification of citizens leads to a form of market citizenship, this would imply that the Marshall framework no longer is comprehensive in dealing with the various forms of citizenship a society can organize. The triumph of market citizenship could even imply that social rights are considered as less relevant, as the distribution of goods and 
services in this case should be governed by market considerations, and not by a discourse on basic rights and moral obligations for society and the political system. Somers (2008) argues that market citizenship has become an important phenomenon, mainly in the United States, where a dominant liberal ethos shapes public policy. If this claim is correct, it should be observed that the social rights concept will be less powerful in the US than in European countries, where allegedly market citizenship is less strongly developed.

While the theory of T.H. Marshall has been influential in numerous European countries, in the United States the impact of his work has remained more limited (Mead, 1997). Marshall's focus on the importance of social rights has also been considered a normative choice to support a strong expansion of welfare state provisions, and some public opinion research suggests that among the US population support for this kind of expansion is but lukewarm (Quadagno \& Pederson, 2012). In the US context, protection from poverty and assurance of adequate living condition are much less frequently seen as rights that should be guaranteed to all citizens, without distinction, by state institutions (Aarøe \& Petersen, 2014). The more limited scope of welfare provisions in the US in comparison to Europe, thus might imply that US citizens are indeed less likely to consider the provision of social goods as a central responsibility for the political system. Partly this could be explained by a more liberal economic concept of citizenship, where market consideration play a larger role than is the case in European societies.

If there is a convergence between public opinion and public policy, this can be explained in two distinct ways. The "regime hypothesis" assumes that public opinion adapts itself to the government policy that is being pursued over a longer period of time (Jæger, 2006). Generous welfare state arrangements will lead to a generalized feeling of entitlement among the population, and therefore these protective measures will be taken for granted. Other studies, however, assume that policy is formed in response to public opinion. Lipset and Marks (2001) have documented a number of reasons why socialism never became a major political force in US politics, including a number of strategic mistakes made by both party and trade union officials in the $19^{\text {th }}$ and early $20^{\text {th }}$ century. The US founding ethos of individualism and individual responsibility is identified by Lipset and Marks as standing in opposition to the collective protection and insurance logic that is inherent to the modern welfare state. Following Lipset and 
Marks's logic leads to the expectation that for US citizens, the protection of social rights receives less support in comparison to their European counterparts. The emphasis on individual freedom and responsibility that is so central to the American ethos would have a negative effect on the public acceptance of collective insurance and redistribution schemes.

In this paper, we do not aim to disentangle the causal relationship between public opinion and policy, as we only have access to cross-sectional data. The ambition of this paper is therefore more limited, as we aim to determine whether public opinion in the US is indeed in congruence with a more restrictive social policy. Our goal is therefore to ascertain whether US public opinion with regard to social rights is distinctive in comparison to European public opinion. While previous studies have tried to explain differences between the US and Europe by investigating conceptions of deservingness, we ascertain to what extent these differences might also be rooted in different concepts of ideal democracy (Alesina \& Angeletos, 2005).

More specifically, we test the hypothesis that US citizens' conception of ideal democracy will place less emphasis on social rights in comparison to Europeans. We test this hypothesis by comparing findings from the European Social Survey in Europe (ESS 2012, 2014) with data from a specific module of the Cooperative Congressional Election Study that was conducted in the US in the Fall of 2014 (CCES, 2014). Both surveys included an identical list of ideal conceptions of democracy, thus allowing for a direct comparison between US and European public opinion. A weaker emphasis on social rights in the US, could be one of the elements that help us to explain the US exceptionalism with regard to social policy.

\section{Data and methods: Investigating democratic ideals}

The European Social Survey in 2012 is one of the first major comparative surveys in which respondents were asked about their expectations on the ideal of democracy. Respondents were presented with a variety of aspects of democracy, and were asked to indicate the importance of each item ("how important do you think it is for democracy in general that..."). The items included in this battery cover diverse aspects of democratic functioning ranging from free and fair elections, the protection of minority 
rights to protecting citizens against poverty. The importance of the diversity of these items for the purpose of testing our hypothesis is that this battery of items also includes social rights, as they were envisioned in the work of T.H. Marshall.

In the United States, exactly the same module was included as part of the Cooperative Congressional Election Study (CCES, 2014) which was conducted just before the Congressional elections of November 2014. The sample for this module was precisely 1,000 respondents. Given our focus on a comparison between the US and its European counterparts, in this study we focus mainly on a comparison between the US sample, and that of the 29 countries that took part in the European Social Survey. As not all these participating countries have a comparable socio-economic status as the US, we also make a comparison with a more restrictive sample of the $21 \mathrm{EU}$ member states that are represented in the ESS dataset. As both the US and the European data can be considered as largely representative of the population, such a direct comparison is empirically warranted. ${ }^{1}$ The gap in the mean scores in Table 1 between the US and the Europe are statistically significant for every indicator, whereas the comparison between the two groupings of ESS countries (the full 29-country sample and the 21-country EU member sample) are indistinguishable (see appendix Figure A1 for documentation of $95 \%$ confidence intervals).

\section{[Table 1 about here]}

When we review the mean values of the items in this battery, a first striking finding in Table 1 is that respondents tend to consider all elements as very important. With just two exceptions (see below) each item receives a score above 7 on a scale from 0 to 10 , indicating that citizens tend to have quite high expectations on democratic ideals. The rule of law (expressed by the item: "The courts treat everyone the same"), is clearly considered as the most important hallmark of a democratic political system with a score of 9.24 in Europe and 8.71 in the United States. Free and fair elections obtain an almost equally high score (8.86 in Europe and 8.55 in the US). Also for the third and the fourth most highly ranked items, we can observe a symmetry between Europe and the US. Public opinion on both sides of the Atlantic, therefore, seem to converge quite strongly on what are the most important characteristics of democracy, and traditional liberal elements like the rule of law, free and fair elections and free media clearly are of paramount importance for most citizens. 
In contrast to the American and European agreement on the rank order of the four most important items, there are major differences in the rank ordering of subsequent items. In Europe, protecting citizens against poverty is still considered as an important characteristic of a democratic system, with a mean score of 8.73 and ranked as the fifth most important item. This is clearly different from the US, where this item ranks $10^{\text {th }}$, with an average score of 6.80. US public opinion, on the other hand, seems to be more sensitive to traditional liberal rights, like the capability of the media and opposition parties to criticize the government. While reducing income inequality clearly is not the highest priority for European respondents (8.26), this item receives the lowest score for US respondents, with an average of 6.26. This simple overview of average scores already suggests that the two items that most clearly represent T.H. Marshall's conception of social rights are clearly ranked very low by US respondents, which is not the case for European respondents. Among all the elements of democracy in the survey, the US score on the social rights items is the lowest that can be observed.

In sum, social rights are not considered by European citizens to be outside the realm of democratic politics, while we find less support for this claim among US respondents. European citizens consider social rights to be highly important for democracy itself, while US citizens regard social rights as much less important. The question remains, however, whether citizens see a distinction between social and formal political rights as inherent to democracy. Here too, we can compare US and European public opinion.

\section{Distinctive democratic ideals: Latent class analysis}

In order to assess whether citizens hold distinctive democratic ideals in terms of the elements of democracy they consider most important, we conducted a latent class analysis (LCA) to identify respondents that are characterized by a similar combination of items in this battery (Hooghe et al., forthcoming; Hooghe \& Oser, forthcoming). The main advantage of LCA for answering our research question is that it allows for the identification of latent structures that are not based on the separate items, but rather on how the individuals responding in the survey combine those items in a distinctive pattern (Collins \& Lanza, 2010). An actor-centered technique like LCA is therefore preferable over an item-based technique like factor analysis or principal component analysis for our study, as we are mainly interested in how individuals make specific combinations of survey items. Latent class analysis therefore allows us to identify 
groups of citizens that adhere to distinctive concepts of democracy in terms of how they combine different items in this battery (Magidson \& Vermunt, 2004). For the purpose of empirically assessing T.H. Marshall's social and political rights concepts, high scores on one set of items (e.g., social rights) are just as distinctive for the identification of these groups as low scores on other items (e.g., political rights). In contrast to more traditional cluster analysis, LCA allows the researcher to determine the optimal number of clusters to be distinguished based on objective goodness of fit criteria while in cluster analysis this is usually the result of a more arbitrary decision (Nylund et al., 2007).

The eleven items listed in Table 1 are included in the latent class analysis. The goodness of fit criteria indicate that the optimal solution distinguishes five groups. These analyses are based on data from 30 countries, and from a comparative perspective it is important to determine the validity of our findings across these societies. To assess measurement equivalence we conducted tests to ascertain the cross-cultural measurement validity of the five constructs (Kankaraš et al. 2010). These tests show that the five group solution is indeed present across these societies, and therefore can be seen as a valid operationalization. This implies that scores between countries can be compared in a valid manner for the interpretation of the distinctive characteristics of the latent classes, as well as the subsequent analyses of sociodemographic characteristics of each group (see appendix for further documentation of latent class analysis method, including analytical code and goodness of fit statistics that inform model selection).

These five groups are depicted in Figure 1, in which the groups are represented in terms of the likelihood that they will consider each specific item to be highly important for democracy. The democracy indicators are ordered on the x-axis from highest to lowest means in the general population, and connective lines are added when useful for distinguishing the distinctive characteristics of a latent class. A clear finding in Figure 1 is that three of these groups consider all items in the survey to be of similar levels of importance. The latent class labeled "high ideals", which includes $24 \%$ of the respondents, identifies a group of citizens who deemed all of the elements of democracy included in the survey to be highly important, without further distinction. This group of respondents gives the maximum score to almost all the items, so we can hardly detect any variation. Conversely, the group labeled "low ideals", which includes $10 \%$ of the respondents, attributed relatively low importance to all the indicators, again without 
any meaningful variation. An additional group labelled "medium ideals" (31\% of the respondents) consistently attributed moderate importance to all indicators and there is no apparent hierarchy in their answers. These findings show that almost two-thirds of the respondents $(65 \%)$ do not attribute special importance to specific elements of democracy, but rather consider all to have similar levels of importance. For analytical purposes, these groups are potentially problematic, because these uniform scores might reflect genuine preferences but we cannot exclude the possibility that these findings reflect survey effects such as responses influenced by social desirability, or an effort to measure a complex construct for which coherent attitudes may not exist.

The two additional latent classes, labeled "social rights" and "political rights" in Figure 1 are theoretically more relevant for testing T.H. Marshall's citizenship theories, as they identify individuals who have contrasting normative conceptions of what is most important for democracy. The "social rights" ideal held by $19 \%$ of the respondents places relatively high importance on democratic values of economic equality (the reduction of income inequality and protection from poverty) and governmental accountability (government explaining its decisions and held accountable in elections). This group of respondents is highly motivated to emphasize social citizenship rights. In contrast, the "political rights" ideal that is held by $16 \%$ of the respondents places relative emphasis on items that correspond to formal political rights in T.H. Marshall's theory, such as the importance of a free and competitive electoral process in which parties are free to criticize the government, and free and reliable media. The contrasting emphases of these two groups are visually clear in the criss-crossing of the connecting lines. The social rights group is highly likely to prioritize reducing poverty and income inequality, while this is less of a priority for the political rights group. In contrast, the political rights group is highly likely to prioritize free media and freedom of parties to oppose and critique the government, which are less of a priority for the "social rights" group.

[Figure 1 about here]

As already noted, the five group solution for the 30 countries in the analysis was found to be characterized by measurement equivalence as necessary for valid cross-group comparison of latent constructs, and this includes the US sample. When we present 
findings for the US respondents only, the distinctive features of the US respondents are clear (Figure 2). While the contrast between the items emphasized by the political rights and the social rights group is already large across the 30-country sample, this contrast is even greater among the US sample. The group that supports political rights has an exceptionally low level of support for fighting poverty and reducing income inequality. American respondents in the political rights group are not merely indifferent about the items related to social rights, but rather they attribute these items very low levels of importance, particularly in comparison to their European counterparts.

[Figure 2 about here]

The analysis thus far has allowed us to identify five distinct groups of respondents in 30 countries that adhere to different democratic ideals. The measurement equivalence tests show that these latent classes are comparable constructs across countries, meaning that we can compare the cross-country distribution of respondents into these groups in a valid manner. Marked differences can be observed between countries (Table 2). A series of chi-square tests that analyzed the distribution of the US population among the five identified latent classes to all other countries in the study show that the distribution in the US is indeed significantly different from that of all other countries, and an expanded version of this table in the appendix includes standard errors and $95 \%$ confidence interval for each entry in order to document statistical significance of comparisons (appendix Table A3). The findings show that the group that is focused on social rights is fairly small in the US, with only $14.76 \%$ of respondents (compared to $19.39 \%$ in the pooled data set, a statistically significant difference). This low score, however, is by no means exceptional, as countries like the Netherlands or Iceland do not differ from the US in a significant manner. The group that emphasizes political rights is much larger in the US, including $26.98 \%$ of American respondents.

[Table 2 about here] 


\section{Characteristics of democratic ideals groups}

\section{Bivariate ideological differences}

A possible critique of the analysis thus far is that the distinction between social and political rights largely coincides with partisan differences. Since the group that emphasizes social rights expresses an ideological preference for more equality, it seems plausible that this group will be synonymous with left-wing ideologies (Miller, 1999). ${ }^{2}$ An emphasis on social rights might serve as an expression of left-wing political ideology. Table 3 investigates whether this is the case by showing the distribution of the democratic ideals identified by LCA among standard left-right ideological placement measures. For both left-wing and right-wing respondents, the table shows their distribution among the five different democratic ideals. For comparative purposes, we have included separate findings for Europe and for the US. For the European sample, we also report on the 21 EU countries only, in order to allow for a strict comparison to countries with a comparable socio-economic status. The distribution shows that for the European sample, it is incorrect to interpret the social rights group to be an expression of a left-leaning ideology. For example, among the respondents who identify as right-wing, the proportion that belongs to the social ideals group is strikingly similar to the mean of all respondents. This finding indicates that a social rights democratic concept that includes reducing poverty and income inequality, is not limited to left-leaning respondents in the European population, but is fairly evenly distributed across the ideological spectrum.

This pattern differs strongly in the United States sample. Left-leaning US respondents are fairly similar to the overall population in terms of their distribution among the different democratic ideals. In addition, there is little difference among the extreme left, moderate left and the center in terms of their distribution among the different types of democratic ideals. Among moderate right and extreme right-leaning US respondents, however, the pattern is starkly different, with very few respondents belonging to the social rights group, and almost half of these respondents belonging to the political rights group. We can observe, therefore, a marked difference between the US and Europe. While in Europe, we find support for social rights across the ideological spectrum, in the US this remains mostly limited to those who situate themselves on the left of the spectrum. 
[Table 3 about here]

\section{Characteristics of latent class group members}

The question remains whether these bivariate relationships between the democratic ideals groups and left-right self-placement remain valid when accounting for additional socio-demographic characteristics. In order to provide a more detailed portrait of the classes we identify, we follow standard analytical practice in the literature to conduct regression analyses to predict membership in these classes (O'Brien \& Noy, 2015; Oser 2016; Hooghe et al. 2016). As our main theoretical interest is the membership in the social and political ideals, Tables 4 and 5 present results of multilevel linear regression analyses with the dependent variable of probability of membership in these latent classes. These findings determine what kind of individual and country-level characteristics help explain whether citizens emphasize a social or political democratic ideal. $^{3}$

For individual-level predictors, in addition to the left-right self-placement we also include control variables that are commonly used to analyze democratic ideals and values (Dalton and Welzel 2014) such as age, education and gender. For country-level predictors, we include level of inequality, measured by the Gini index, as calculated from income surveys conducted by the Luxembourg Income Study (LIS, 2015) that is available for 22 of the countries in the sample. An additional country-level factor is democratic stability, as measured by the Polity IV dataset (Marshall et al. 2013). Since the number of country-level observations is limited, we analyze the country-level variables separately (see descriptive statistics in the appendix).

[Table 4 about here]

[Table 5 about here]

The findings provide a more detailed portrait of social and political group members. The relationship with left-right self-placement remains significant with additional controls, with the social ideal members scoring on the left side of the continuum, and the political ideal members scoring on the right. As we would expect from the findings above, the relationship is substantively fairly small, which indicates that political and 
social rights ideals do no not fully overlap with respondents' left-right ideology. There is no age distinction for either group, though there is a clear gender effect by which women are more likely to hold social rights ideals, while men are more likely to express political rights ideals. A difference is also evident for education, with a positive relationship evident for the political rights group, whereas the social rights group is associated with lower education levels.

At the country level we see the controls are significant in expected directions. Democratic stability is measured by number of democratic years, with more mature democracies showing a lower prevalence of social ideals but a higher prevalence of political ideals. Higher income inequality is associated with a stronger emphasis on social rights, whereas lower income inequality is associated with more support for political rights. For the US, however, we are confronted with the remarkable observation that despite the rather high level of income inequality, this does not seem to lead to stronger support for social rights.

\section{Conclusion}

In 1883, the German chancellor von Bismarck established the first comprehensive system of sickness insurance for workers and this system has been credited with providing basic stability for German society. When president Obama tried to follow that example some 130 years later, he met with fierce resistance in Congress, and also to some extent in public opinion. This comparison raises the question posed by Lipset and Marks (2001): why didn't it happen here? Why didn't the United States develop a system of universal health care coverage comparable to most other developed democracies? In this study, we investigated one potential explanation using public opinion data, namely, we ask whether US citizens are more reluctant than their European counterparts to consider social rights as an important part of a fully mature democratic system. To answer this question, we compared existing data from the European Social Survey with a survey that was specifically designed to ask parallel questions through the CCES to US respondents.

A first, important finding is that the structure of democratic ideals is comparable across societies investigated in this study for the purposes of cross-national comparison. The 
United States clearly is not an exception in this regard, as US respondents still see fighting poverty and reducing inequality as an important part of the democratic ideal, even though Americans consider these social rights to be less important in comparison to Europeans. In other words, American exceptionalism is not strong enough that it eliminates the social rights ideal that is so central in the work of T.H. Marshall. The distinction between political and social rights as understood by Marshall remains meaningful among public opinion for a wide array of contemporary democracies, both in Europe as well as in the United States.

What does make the United States exceptional compared with industrialized states in Europe, however, is the fact that support for social rights is comparatively limited. On a purely descriptive basis, one can already observe that reducing poverty and income inequality is attributed relatively low importance in the United States as part of citizens' ideals regarding important elements of democracy. It is noteworthy that the explanation for the low level of support for reducing income inequality is likely to be different in the United States than in other countries that also place relatively low importance on social rights. In the case of countries like Sweden (Gini coefficient .281), Belgium (.268) or Norway (.252) the relatively low support for a further reduction of income inequality amounts to a ceiling effect as these countries already have a rather egalitarian income structure. As Marshall $(1964,117)$ noted: "We are not aiming at absolute equality. There are limits inherent in the egalitarian movement." But among the 24 traditional OECD member states, the United States in fact has the highest level of income inequality with a Gini coefficient of .396 , followed by Estonia with .361 . This is an exceptionally high figure, and it seems plausible that this unusually high level of inequality could serve as an incentive to place more emphasis on fighting income inequality. The data show, however, that exactly the opposite occurs, and that support for social rights remains rather limited in US public opinion. It has been argued that US public opinion generally favors allowing market forces to influence how citizenship rights can be exercised, and our results concur with this argument, despite the exceptionally high level of inequality.

The findings in this study show that the low level of average support for social rights in the United States is manifested in two ways. First, the latent class that emphasizes social rights includes a comparatively small proportion of the population in the US 
context, relative to comparable countries in Europe. Just as important is the fact that when the US is analyzed separately, among the group that emphasizes political rights the scores for the "social" items are extremely low. This means that for the American citizens who place a special emphasis on political rights, social rights play a negligible role in terms of their vision of important components of democracy. This is in line with the literature on market citizenship, which stresses that in highly competitive market economies, the attribution of full citizenship is largely left to the functioning of market forces. Whether or not a concept of market citizenship indeed pushes out the social concept of citizenship rights, however, is a topic that requires further research. The idea that there is a historical development of distinct citizenship concepts is largely in line with the logic that prevails in Marshall's original framework, so it would indeed be worthwhile to investigate the development of new, more economically-focused forms of citizenship concepts in future research. It has to be noted that the concept of "market citizenship" has been introduced in the theoretical literature, but that we still lack a solid measurement instrument for this idea. In future survey research, therefore, it should also be questioned whether respondents see the service delivery by the political system, and the market logic governing this function as an element of democracy. If this form of market citizenship is measured simultaneously with the more traditional concepts of political and social citizenship, this should allow us to arrive at an empirically founded conclusion to the question whether forms of market citizenship indeed drive out these Marshall-inspired forms of democratic citizenship.

The current study offers a first step in the explanation of why the United States is such a distinct society when it comes to social security and income redistribution. What we can observe is that in the US these policies are congruent with public opinion preferences that prioritize the importance of classic political rights over social rights. It is obvious that in the United States in 2014, support for social rights can be identified among public opinion, but support is significantly weaker than in Europe. Due to the cross-sectional nature of the data analyzed in the current study, we cannot determine the causal mechanisms that leads to this congruence. The regime hypothesis would argue that US citizens have learned over time not to expect strong government intervention on these issues. Why this is the case could be a matter of historical investigations on factors such as presidential power, the absence of a socialist party, or the weakness of trade unions (Lipset \& Marks, 2001). Other authors would argue that 
the US political system receives less pressure from public opinion to extend social rights, as this kind of social protest would run against the US ethos that promotes individual freedom and opportunity. This kind of preference is more strongly associated with forms of market citizenship. The current study's findings of distinct patterns in US public opinion on these matters renders it promising to gather the requisite longitudinal data in future studies in order to investigate whether there is a causal relation between policy and opinion beyond the association that is demonstrated in this article. What we can say based on the results of the current analysis is that the outlier status of the United States, compared to other highly industrialized societies, is by no means merely the result of coincidence of or specific electoral results. Both with regard to public opinion, as with regard to policy, the US is distinct from other OECD member states, and this by itself suggests that this outlier status is rather structural. Further research, based on longitudinal data, however, should allow us to determine the exact causal order in this relation, in order to arrive at a more comprehensive explanation of this form of American exceptionalism.

The findings of the current study show, however, that an emphasis on social rights is present not only among the far left in the US, but is shared fairly equally among the moderate left and centrists as well. While protests such as "Occupy" seemed to draw upon the far left in particular, it would seem that the surprising success of the populist economic messages during the 2016 presidential campaign, voiced in different ways in the campaigns of Bernie Sanders and Donald Trump, also drew upon the moderate left and centrist voters who align with their European counterparts in their emphasis of the importance of social rights (Bonikowski \& Gidron, 2016). No matter what the exact causal mechanism could be, the congruence between policy and public opinion preference allows us to predict that politicians who want to expand the scope of the state system in the U.S. will face an uphill battle. While previous research has focused mainly on institutional elements in order to explain American exceptionalism on these matters (Teles, 1998), our findings suggest that further research on public opinion can also play an important role in understanding this puzzle. 


\section{References}

Aarøe, L., \& Petersen, M. (2014). Crowding Out Culture: Scandinavians and Americans Agree on Social Welfare in the Face of Deservingness Cues. Journal of Politics, 76(3), 684-697.

Agresti, A. (2007). An Introduction to Categorical Data Analysis (2nd ed.). Hoboken, N.J.: Wiley.

Alesina, A. \& Angeletos, G.M. (2005). Fairness and redistribution. American Economic Review, 95(4), 960-980.

Alesina, A. \& Glaeser, E. (2004). Fighting Poverty in the US and Europe. A World of Difference. Oxford: Oxford University Press.

Ariely, G. (2011). Exploring citizenship spheres of inclusion/exclusion: rights as 'potential for power'. Patterns of Prejudice, 45(3), 241-258.

Bonikowski, B., \& Gidron, N. (2016). The Populist Style in American Politics: Presidential Campaign Discourse, 1952-1996. Social Forces, 94(4), 15931621.

Bulmer, M., \& Rees, A. (eds., 1996). Citizenship Today. The Contemporary Relevance of T.H. Marshall. London: UCL Press.

CCES (2014). Team module of the Cooperative Congressional Election Study. Cambridge: Harvard University.

Collins, L. M., \& Lanza, S. T. (2010). Latent class and latent transition analysis: With applications in the social, behavioral, and health sciences. Hoboken: Wiley.

Connell, A. (2012). Civil Rights and Social Welfare: Some Thoughts on the Contemporary Relevance of T. H. Marshall. Political Quarterly, 83(3), 551559.

Corman, J., \& Levin, D. (2016). Support for Government Provision of Health Care and the Patient Protection and Affordable Care Act. Public Opinion Quarterly, 80(1), 114-179.

Cox, R.H. (1998). The Consequences of Welfare Reform: How Conceptions of Social Rights are Changing. Journal of Social Policy, 27(1), 1-16.

Dalton, R., \& Welzel, C. (Eds.). (2014). The civic culture transformed: From allegiant to assertive citizens. Cambridge: Cambridge University Press.

Deckard, N. \& Heslin, A. (2016). After Postnational Citizenship: Constructing the Boundaries of Inclusion in Neoliberal Contexts. Sociology Compass, 10(4), 294-305. 
Esping-Andersen, G. (1990). The Three Worlds of Welfare Capitalism. Princeton: Princeton University Press.

ESS Round 6 (2012). European Social Survey Round 6 (ESS-6) 2012, data file edition 2.1. Norway: Norwegian Social Science Data Services.

ESS Round 6 (2014). European Social Survey Round 6 (ESS-6) 2012 documentation report, edition 2.1. Bergen, European Social Survey Data Archive: Norwegian Social Science Data Services.

Fraser, N. \& Gordon, L. (1992). Contract versus Charity. Why is there no social citizenship in the United States? Socialist Review, 22(1), 45-68.

Fudge, J. (2005). After Industrial Citizenship: Market Citizenship or Citizenship at Work? Relations Industrielles/Industrial Relations, 60(4), 631-656.

Garfinkel, I., Rainwater, L. \& Smeeding, T. (2010). Wealth and Welfare States: Is America a Laggard or Leader? New York: Oxford University Press.

Hicks, A. \& Swank, D. (1992). Politics, Institutions, and Welfare Spending in Industrialized Democracies, 1960-82. American Political Science Review, 86(3), 658-674.

Hooghe, M., Marien, S., \& Oser, J. (Forthcoming). Great expectations: the effect of democratic ideals on political trust in European democracies. Contemporary Politics, 1-17.

Hooghe, M., \& Oser, J. (Forthcoming). Social and political citizenship in European public opinion: An empirical analysis of T.H. Marshall's concept of social rights. Government and Opposition

Hooghe, M., Oser, J., \& Marien, S. (2016). A comparative analysis of 'good citizenship': A latent class analysis of adolescents' citizenship norms in 38 countries. International Political Science Review, 37(1), 115-129.

Jacobs, L., \& Skocpol, T. (2015). Health care reform and American politics: what everyone needs to know (3rd ed.): Oxford University Press.

Jæger, M. M. (2006). Welfare Regimes and Attitudes Towards Redistribution: The Regime Hypothesis Revisited. European Sociological Review, 22(2), 157-170.

Jæger, M. M. (2009). United But Divided: Welfare Regimes and the Level and Variance in Public Support for Redistribution. European Sociological Review, 25(6), 723-736.

Kang, S.-G., \& Powell, G. B. (2010). Representation and policy responsiveness: The median voter, election rules, and redistributive welfare spending. Journal of Politics, 72(4), 1014-1028. 
Kankaraš, M., Moors, G., \& Vermunt, J. K. (2010). Testing for measurement invariance with latent class analysis. In E. Davidov, P. Schmidt \& J. Billiet (Eds.), Cross-Cultural Analysis: Methods and Applications (pp. 359-384). New York: Routledge.

Kankaraš, M., \& Vermunt, J. K. (2014). Simultaneous latent class analysis across groups. In A. C. Michalos (Ed.), Encyclopedia of Quality of Life and WellBeing Research. Heidelberg: Springer.

Korpi, W. (1989). Power, Politics, and State Autonomy in the Development of Social Citizenship. Social Rights during Sickness in 18 OECD countries. American Sociological Review, 54(3), 309-328.

Korpi, W., \& Palme, J. (2003). New politics and class politics in the context of austerity and globalization: Welfare state regress in 18 countries, 1975-95. American Political Science Review, 97(3), 425-446.

Lipset, S.M. \& Marks, G. (2001). It didn't happen here: Why socialism failed in the United States. New York: Norton.

LIS, Luxembourg Income Survey (2015). Inequality and Poverty Key Figures. Available from http://www.lisdatacenter.org/lis-ikf-webapp/app/search-ikffigures, accessed June 19, 2015.

Magidson, J., \& Vermunt, J.K. (2004). Latent class models. In D. Kaplan (Ed.), The Sage handbook of quantitative methodology for the social sciences (pp. 175198). London: Sage.

Marshall, T.H. (1950). Citizenship and social class and other essays. Cambridge: Cambridge University Press.

Marshall, T.H. (1964). Class, Citizenship, and Social Development. Garden City: Doubleday.

Marshall, M. G., Gurr, T. R., \& Jaggers, K. (2013). POLITY IV Project: Political Regime Characteristics and Transitions, 1800-2013. Vienna: Center for Systemic Peace. Retrieved from http://www.systemicpeace.org/inscrdata.html, accessed February 9, 2015.

Mead, L. (1997). Citizenship and Social Policy: T. H. Marshall and Poverty. Social Philosophy and Policy, 14(2), 197-230.

Mettler, S. (2011). The submerged state: How invisible government policies undermine American democracy. Chicago: University of Chicago.

Miller, D. (1999). Principles of social justice: Cambridge: Harvard University Press.

Nussbaum, M. \& Sen, A. (eds., 1993). The Quality of Life. Oxford: Oxford University Press. 
Nylund, K. L., Asparouhov, T., \& Muthén, B. O. (2007). Deciding on the number of classes in latent class analysis and growth mixture modeling: A Monte Carlo simulation study. Structural Equation Modeling, 14(4), 535-569.

Obama, B. (2016). United States health care reform: Progress to date and next steps. Journal of the American Medical Association, 316(5), 525-532.

O’Brien, T. \& Noy, S. (2015). Traditional, Modern, and Post-Secular Perspectives on Science and Religion in the United States. American Sociological Review, 80(1), 92-115.

OECD (2016). Social Expenditure Update (November 2016). Paris: OECD.

Oser, J. (2016). Assessing how participators combine acts in their "political tool kits": A person-centered measurement approach for analyzing citizen participation. Social Indicators Research, 1-24. In press: http://dx.doi.org/10.1007/s11205016-1364-8.

Quadagno, J. \& Pederson, J.-E. (2012). Has support for Social Security declined? Attitudes toward the public pension scheme in the USA, 2000 and 2010. International Journal of Social Welfare, 21(s1), s88-s100.

Revi, B. (2014). TH Marshall and his critics: reappraising 'social citizenship' in the twenty-first century. Citizenship Studies, 18(3-4), 452-464.

Scruggs, L. \& Allan, J. (2006). The Material Consequences of Welfare States. Benefit Generosity and Absolute Poverty in 16 OECD Countries. Comparative Political Studies, 39(7), 880-904.

Somers, M. (2008). Genealogies of Citizenship: Markets, Statelessness, and the Right to Have Rights. New York: Cambridge University Press.

Teles, S. (1998). Why is there no Affirmative Action in Britain? American Behavioral Scientist, 41(7), 1004-1026. 
Table 1. Mean scores on "democratic ideals" battery

\begin{tabular}{|c|c|c|c|c|c|}
\hline Description & Abbreviation & $\begin{array}{l}\text { Eur. } \\
\text { mean }\end{array}$ & $\begin{array}{c}\mathbf{E U} \\
\text { mean }\end{array}$ & $\begin{array}{c}\text { US } \\
\text { mean }\end{array}$ & $\begin{array}{c}\text { US } \\
\text { order }\end{array}$ \\
\hline 1. The courts treat everyone the same & courts fair & 9.24 & 9.33 & 8.71 & 1 \\
\hline 2. The government explains its decisions to voters & govt expl. & 8.88 & 9.01 & 8.27 & 3 \\
\hline 3. National elections are free and fair & fair elec. & 8.86 & 8.95 & 8.55 & 2 \\
\hline $\begin{array}{l}\text { 4. The media provide citizens with reliable information to } \\
\text { judge the government }\end{array}$ & media info. & 8.75 & 8.77 & 8.24 & 4 \\
\hline 5. The government protects all citizens against poverty & poverty & 8.73 & 8.76 & 6.80 & 10 \\
\hline $\begin{array}{l}\text { 6. Governing parties are punished in elections when they } \\
\text { have done a bad job }\end{array}$ & party acc. & 8.48 & 8.57 & 7.74 & 5 \\
\hline 7. The rights of minority groups are protected & minority & 8.27 & 8.53 & 7.40 & 9 \\
\hline $\begin{array}{l}\text { 8. The government takes measures to reduce differences in } \\
\text { income levels }\end{array}$ & income eq. & 8.26 & 8.27 & 6.26 & 11 \\
\hline 9. Opposition parties are free to criticise the government & opposition & 8.22 & 8.19 & 7.58 & 7 \\
\hline 10. The media are free to criticise the government & free media & 8.09 & 8.07 & 7.62 & 6 \\
\hline $\begin{array}{l}\text { 11. Different political parties offer clear alternatives to one } \\
\text { another }\end{array}$ & party alter. & 7.97 & 7.95 & 7.55 & 8 \\
\hline
\end{tabular}

Notes: ESS 2012, 29 countries ( $n=48,805)$; ESS 2012, 21 European Union (EU) countries only $(n=37,156)$; CCES 2014 for the US (n=944). Appropriate weights applied; for ESS, design weight (dweight) and population size weight (pweight); for CCES, design weight (weight). Prefatory survey question: "Using this card, please tell me how important you think it is for democracy in general that...". Responses coded on a 0 to 10 scale where 0 indicates "not at all important" and 10 indicates "extremely important". Indicators are listed in descending order of means in Europe; right-hand column lists the rank ordering for the US data. 
Table 2. Democratic ideals: distribution of citizens in Europe and the US

\begin{tabular}{lrrrrrr}
\hline & Social & Political & High & Medium & Low & $\mathrm{n}$ \\
\hline Albania & 33.33 & 6.87 & 46.02 & 12.90 & 0.88 & 1,201 \\
Belgium & 18.42 & 15.52 & 12.51 & 40.39 & 13.16 & 1,869 \\
Bulgaria & 21.15 & 18.76 & 39.50 & 16.90 & 3.70 & 2,260 \\
Switzerland & 19.41 & 21.39 & 12.60 & 39.65 & 6.95 & 1,493 \\
Cyprus & 18.89 & 11.64 & 41.09 & 26.18 & 2.18 & 1,116 \\
Czech Republic & 17.69 & 17.63 & 17.46 & 30.46 & 16.76 & 2,009 \\
Germany & 18.54 & 31.88 & 15.93 & 29.10 & 4.54 & 2,958 \\
Denmark & 15.93 & 31.00 & 16.48 & 33.88 & 2.70 & 1,650 \\
Estonia & 17.39 & 14.62 & 27.54 & 28.99 & 11.47 & 2,380 \\
Spain & 29.02 & 6.52 & 32.02 & 25.94 & 6.49 & 1,889 \\
Finland & 18.92 & 16.16 & 11.52 & 43.07 & 10.33 & 2,197 \\
France & 19.56 & 13.51 & 17.07 & 39.48 & 10.38 & 1,968 \\
United Kingdom & 19.12 & 12.19 & 19.26 & 36.01 & 13.42 & 2,286 \\
Hungary & 15.97 & 11.55 & 37.92 & 21.47 & 13.10 & 2,014 \\
Ireland & 15.93 & 11.84 & 21.79 & 34.00 & 16.44 & 2,628 \\
Israel & 20.03 & 15.77 & 23.69 & 34.41 & 6.10 & 2,508 \\
Iceland & 15.33 & 27.53 & 23.89 & 28.56 & 4.69 & 752 \\
Italy & 28.75 & 10.81 & 26.23 & 29.91 & 4.30 & 960 \\
Lithuania & 16.52 & 11.99 & 22.88 & 30.26 & 18.35 & 2,109 \\
Netherlands & 12.34 & 19.38 & 9.25 & 44.72 & 14.31 & 1,845 \\
Norway & 17.72 & 26.39 & 17.29 & 34.63 & 3.97 & 1,624 \\
Poland & 27.06 & 16.48 & 27.16 & 25.62 & 3.69 & 1,898 \\
Portugal & 18.03 & 4.47 & 29.28 & 25.51 & 22.71 & 2,151 \\
Russia & 21.03 & 12.39 & 26.35 & 24.03 & 16.19 & 2,484 \\
Sweden & 13.50 & 31.09 & 24.59 & 27.27 & 3.55 & 1,847 \\
Slovenia & 32.93 & 10.59 & 21.27 & 29.91 & 5.30 & 1,257 \\
Slovakia & 13.76 & 12.52 & 15.90 & 38.14 & 19.68 & 1,847 \\
Ukraine & 22.40 & 10.80 & 31.98 & 27.52 & 7.30 & 2,178 \\
Kosovo & 20.94 & 7.11 & 41.03 & 22.04 & 8.88 & 1,295 \\
United States & 14.76 & 26.98 & 11.94 & 24.97 & 21.34 & 1,000 \\
\hline TOTAL & 19.39 & 16.11 & 23.64 & 30.54 & 10.24 & 55,673 \\
\hline
\end{tabular}

Source: ESS 2012 merged with CCES, $2014(\mathrm{n}=55,115)$. Missing data on the democratic ideals battery constitutes only $0.2 \%$ of US respondents $(n=2)$ and $1 \%$ of European cases $(n=556)$.

Notes: Entries are latent class analysis findings for distribution of population in each country among the five latent classes, with weights applied. Note that each row totals $100 \%$ of the country's population. 
Table 3. Left-right position and democratic ideals typology

29 European countries - all countries in the ESS 2012

\begin{tabular}{lccrrrr} 
& $\begin{array}{c}\text { Social } \\
\text { Ideals }\end{array}$ & $\begin{array}{c}\text { Political } \\
\text { Ideals }\end{array}$ & $\begin{array}{c}\text { High } \\
\text { Ideals }\end{array}$ & $\begin{array}{c}\text { Medium } \\
\text { Ideals }\end{array}$ & $\begin{array}{c}\text { Low } \\
\text { Ideals }\end{array}$ & \multicolumn{1}{c}{ N } \\
\hline All respondents & 19.27 & 17.13 & 22.59 & 31.08 & 9.94 & 46,457 \\
\hline Extreme left & 21.82 & 13.93 & 33.79 & 24.71 & 5.76 & 5,588 \\
Moderate left & 18.06 & 19.11 & 21.88 & 30.57 & 10.38 & 8,213 \\
Center & 20.67 & 14.23 & 22.21 & 30.95 & 11.94 & 15,400 \\
Moderate right & 16.67 & 20.39 & 16.33 & 34.85 & 11.76 & 9,265 \\
Extreme right & 19.12 & 19.02 & 23.73 & 31.73 & 6.40 & 7,991 \\
\hline
\end{tabular}

21 European Union countries in the ESS 2012

\begin{tabular}{lccrrrr} 
& $\begin{array}{c}\text { Social } \\
\text { Ideals }\end{array}$ & $\begin{array}{c}\text { Political } \\
\text { Ideals }\end{array}$ & $\begin{array}{c}\text { High } \\
\text { Ideals }\end{array}$ & $\begin{array}{c}\text { Medium } \\
\text { Ideals }\end{array}$ & $\begin{array}{c}\text { Low } \\
\text { Ideals }\end{array}$ & \multicolumn{1}{c}{ N } \\
\hline All respondents & 18.78 & 17.23 & 21.63 & 31.72 & 10.64 & 35,510 \\
\hline Extreme left & 21.58 & 14.30 & 33.17 & 24.61 & 6.34 & 4,437 \\
Moderate left & 17.94 & 18.82 & 22.35 & 30.54 & 10.35 & 6,592 \\
Center & 20.78 & 14.23 & 21.13 & 31.25 & 12.61 & 11,983 \\
Moderate right & 15.69 & 20.13 & 15.64 & 36.12 & 12.42 & 7,129 \\
Extreme right & 17.32 & 20.31 & 20.77 & 33.91 & 7.68 & 5,369 \\
\hline
\end{tabular}

\section{United States only}

\begin{tabular}{lrrrrrr} 
& $\begin{array}{c}\text { Social } \\
\text { Ideals }\end{array}$ & $\begin{array}{c}\text { Political } \\
\text { Ideals }\end{array}$ & $\begin{array}{c}\text { High } \\
\text { Ideals }\end{array}$ & $\begin{array}{c}\text { Medium } \\
\text { Ideals }\end{array}$ & $\begin{array}{c}\text { Low } \\
\text { Ideals }\end{array}$ & \multicolumn{1}{c}{ N } \\
\hline All respondents & 15.38 & 27.94 & 12.03 & 25.71 & 18.93 & 901 \\
\hline Extreme left & 12.88 & 23.20 & 27.42 & 25.26 & 11.23 & 84 \\
Moderate left & 17.86 & 21.66 & 18.73 & 23.39 & 18.37 & 199 \\
Center & 19.47 & 22.09 & 10.21 & 30.41 & 17.82 & 305 \\
Moderate right & 13.43 & 35.37 & 7.83 & 21.96 & 21.42 & 209 \\
Extreme right & 3.14 & 43.46 & 6.16 & 24.56 & 22.68 & 104 \\
\hline
\end{tabular}

Source: ESS 2012 and CCES, 2014. Sample sizes for each table reflect missing data for left-right placement variable of $14.43 \%$ for the merged sample ( $9.9 \%$ for the US only). A left-right placement scale question is included in both surveys; for the ESS the scale ranges from 0 to 10 , whereas the CCES scale ranges from 1 to 5 . The ESS scale was recoded to a 5-point measure to harmonize with the CCES scale. 
Table 4. Characteristics of social ideals groups in 30 countries

\begin{tabular}{|c|c|c|c|}
\hline & (1) & (2) & (3) \\
\hline $\begin{array}{l}\text { Gender } \\
(1=\text { female })\end{array}$ & $\begin{array}{c}0.033^{* * *} \\
(0.003)\end{array}$ & $\begin{array}{c}0.033^{* * * *} \\
(0.003)\end{array}$ & $\begin{array}{c}0.036^{* * *} \\
(0.003)\end{array}$ \\
\hline Age & $\begin{array}{c}0.000 \\
(0.000)\end{array}$ & $\begin{array}{l}0.000^{* * *} \\
(0.000)\end{array}$ & $\begin{array}{l}0.000^{* * *} \\
(0.000)\end{array}$ \\
\hline $\begin{array}{l}\text { Education }(r e f=l o w) \\
\text { Medium }\end{array}$ & $\begin{array}{c}-0.014^{* * *} \\
(0.004)\end{array}$ & $\begin{array}{l}-0.011^{* *} \\
(0.004)\end{array}$ & $\begin{array}{l}-0.012^{* *} \\
(0.004)\end{array}$ \\
\hline High & $\begin{array}{c}-0.060^{* * *} \\
(0.004)\end{array}$ & $\begin{array}{c}-0.057^{* * *} \\
(0.004)\end{array}$ & $\begin{array}{c}-0.065^{* * *} \\
(0.005)\end{array}$ \\
\hline $\begin{array}{l}\text { Left-right } \\
(1=\text { far left, } 5=\text { far right })\end{array}$ & $\begin{array}{c}-0.007^{* * *} \\
(0.001)\end{array}$ & $\begin{array}{c}-0.006^{* * *} \\
(0.001)\end{array}$ & $\begin{array}{c}-0.007^{* * *} \\
(0.001)\end{array}$ \\
\hline $\begin{array}{l}\text { Country level variables } \\
\text { Democracy in years }\end{array}$ & & $\begin{array}{l}-0.001^{*} \\
(0.000)\end{array}$ & \\
\hline Gini coefficient & & & $\begin{array}{l}0.436^{*} \\
(0.198)\end{array}$ \\
\hline Constant & $\begin{array}{c}0.207^{* * *} \\
(0.007)\end{array}$ & $\begin{array}{c}0.232^{* * *} \\
(0.016)\end{array}$ & $\begin{array}{c}0.059 \\
(0.059)\end{array}$ \\
\hline Observations & 46971 & 46272 & 37392 \\
\hline
\end{tabular}


Table 5. Characteristics of political ideals group members in 30 countries

\begin{tabular}{|c|c|c|c|}
\hline & (1) & (2) & (3) \\
\hline $\begin{array}{l}\text { Gender } \\
(1=\text { female })\end{array}$ & $\begin{array}{l}-0.060^{* * * *} \\
(0.003)\end{array}$ & $\begin{array}{l}-0.053^{* * * *} \\
(0.003)\end{array}$ & $\begin{array}{c}-0.062^{* * * *} \\
(0.003)\end{array}$ \\
\hline Age & $\begin{array}{l}-0.000^{* *} \\
(0.000)\end{array}$ & $\begin{array}{l}-0.000^{* *} \\
(0.000)\end{array}$ & $\begin{array}{l}-0.000^{* * *} \\
(0.000)\end{array}$ \\
\hline $\begin{array}{l}\text { Education }(r e f=l o w) \\
\text { Medium }\end{array}$ & $\begin{array}{l}0.053^{* * *} \\
(0.003)\end{array}$ & $\begin{array}{l}0.064^{* * *} \\
(0.004)\end{array}$ & $\begin{array}{l}0.074^{* * *} \\
(0.004)\end{array}$ \\
\hline High & $\begin{array}{l}0.173^{* * *} \\
(0.004)\end{array}$ & $\begin{array}{l}0.172^{* * *} \\
(0.004)\end{array}$ & $\begin{array}{l}0.192^{* * *} \\
(0.004)\end{array}$ \\
\hline $\begin{array}{l}\text { Left-right } \\
(1=\text { far left, } 5=\text { far } \\
\text { right })\end{array}$ & $\begin{array}{l}0.011^{* * *} \\
(0.001)\end{array}$ & $\begin{array}{l}0.012^{* * *} \\
(0.001)\end{array}$ & $\begin{array}{l}0.013^{* * *} \\
(0.001)\end{array}$ \\
\hline $\begin{array}{l}\text { Country level variables } \\
\text { Democracy in years }\end{array}$ & & $\begin{array}{l}0.001^{* * *} \\
(0.000)\end{array}$ & \\
\hline Gini coefficient & & & $\begin{array}{l}-0.699^{*} \\
(0.335)\end{array}$ \\
\hline Constant & $\begin{array}{l}0.124^{* * *} \\
(0.006)\end{array}$ & $\begin{array}{l}0.049^{*} \\
(0.021)\end{array}$ & $\begin{array}{l}0.334^{* * *} \\
(0.100)\end{array}$ \\
\hline Observations & 46971 & 46272 & 37392 \\
\hline
\end{tabular}

Source: ESS 2012 and CCES, 2014. Standard errors in parentheses ${ }^{*} p<0.05,{ }^{* *} p<0.01,{ }^{* * *} p<0.001$ 
Figure 1. Democratic ideals held by five latent groups of citizens in 30 countries

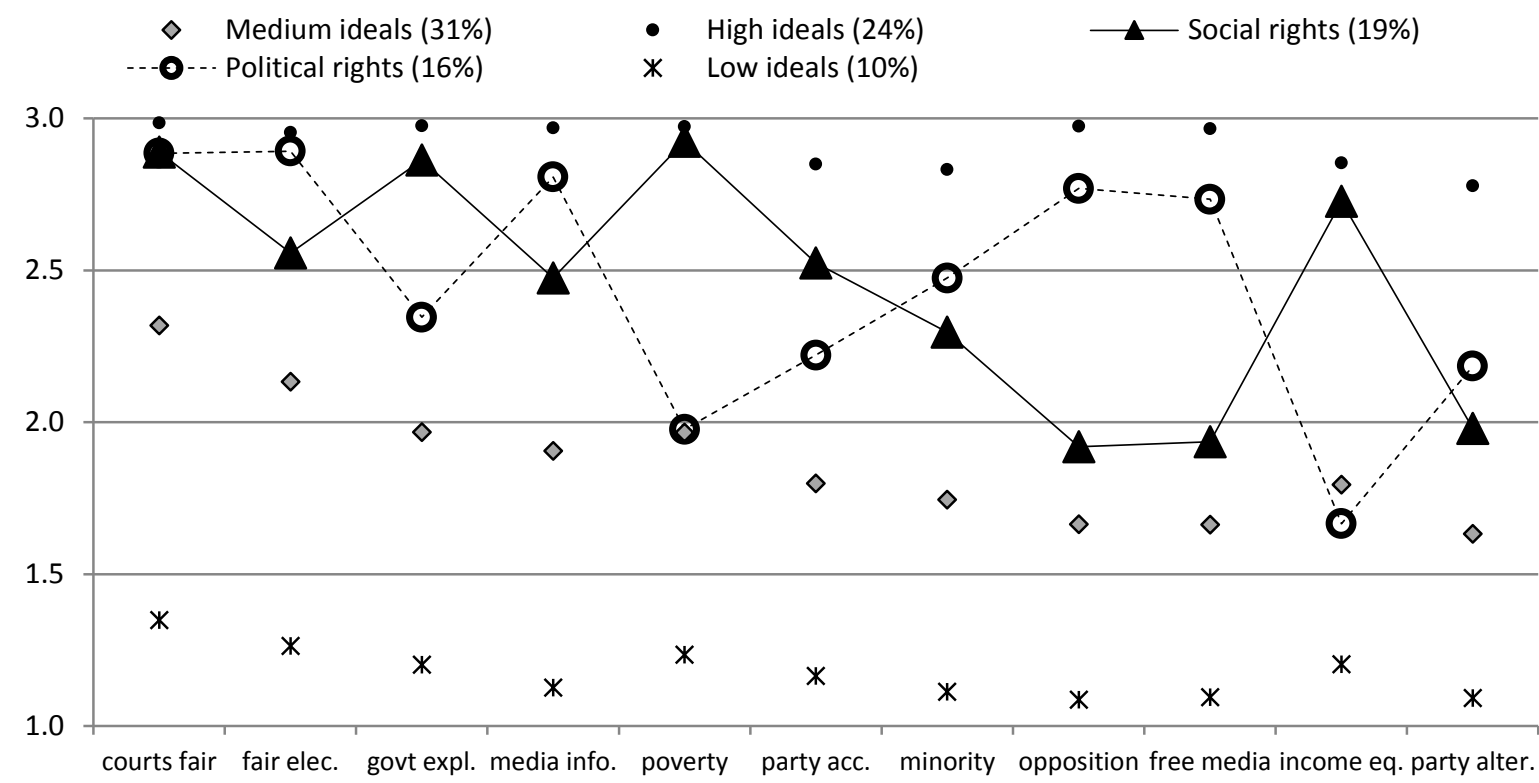

Notes: European Social Survey, $2012(\mathrm{n}=54,673)$ merged with CCES, $2014(\mathrm{n}=1,000)$. The $\mathrm{x}$-axis indicators are organized from left to right by decreasing means in the pooled dataset. The y-axis plots the conditional probabilities that members of a latent class will consider the democracy indicators to be important for democracy, with connective lines to aid interpretation of complex democratic ideals. The $\mathrm{y}$-axis scale is based on 3-point coding of the original 11-category items conducted to address issues of sparse data in analyzing categorical variables (Agresti, 2008). See appendix for further documentation of latent class analysis analytics, including model selection, measurement equivalence tests and robustness tests. 
Figure 2. Democratic ideals - US only

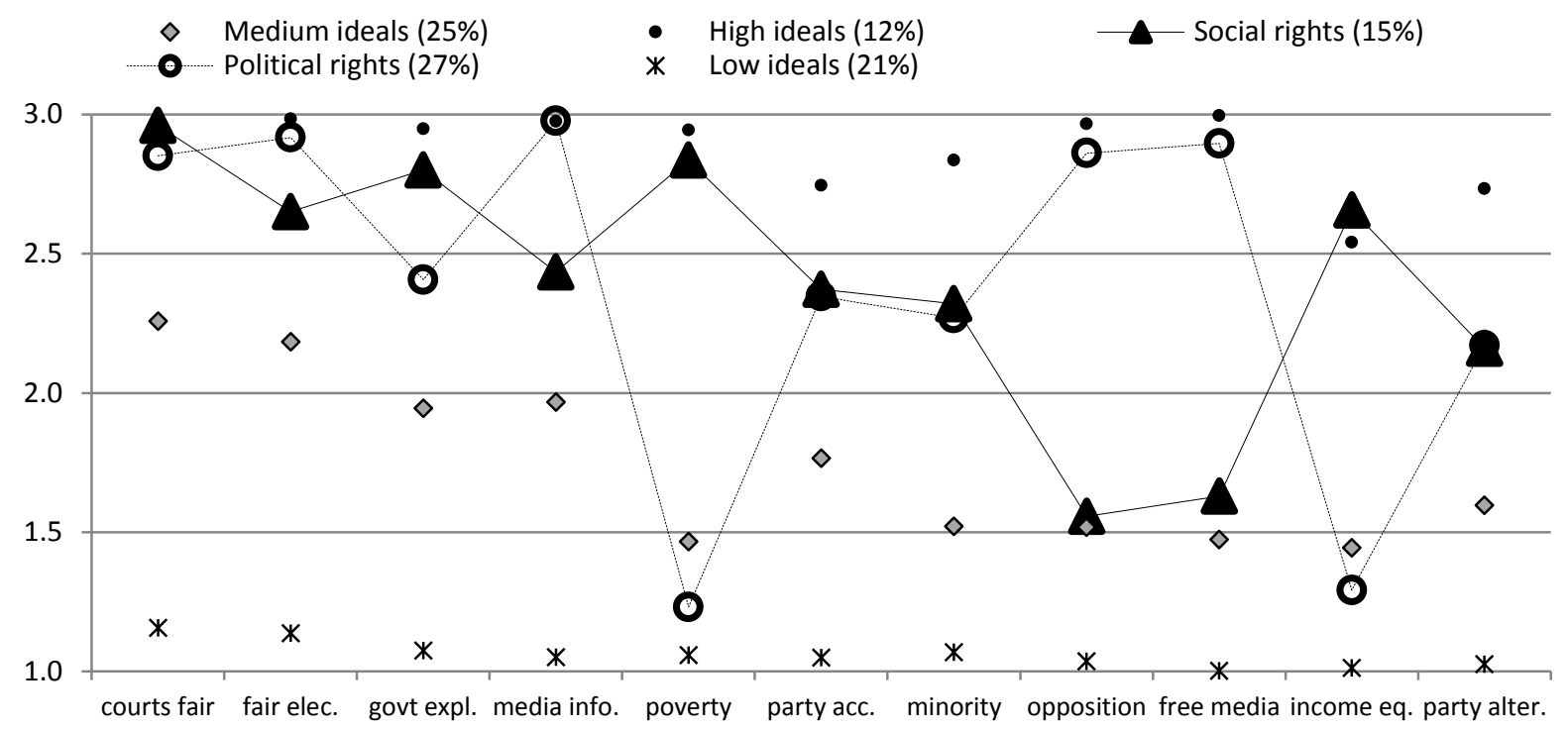

Source: CCES, $2014(\mathrm{n}=1,000)$. For methods: see Figure 1. 


\section{Appendix}

\section{A1. Democratic ideal mean scores}

Figure A1. Democratic ideal mean scores including confidence intervals

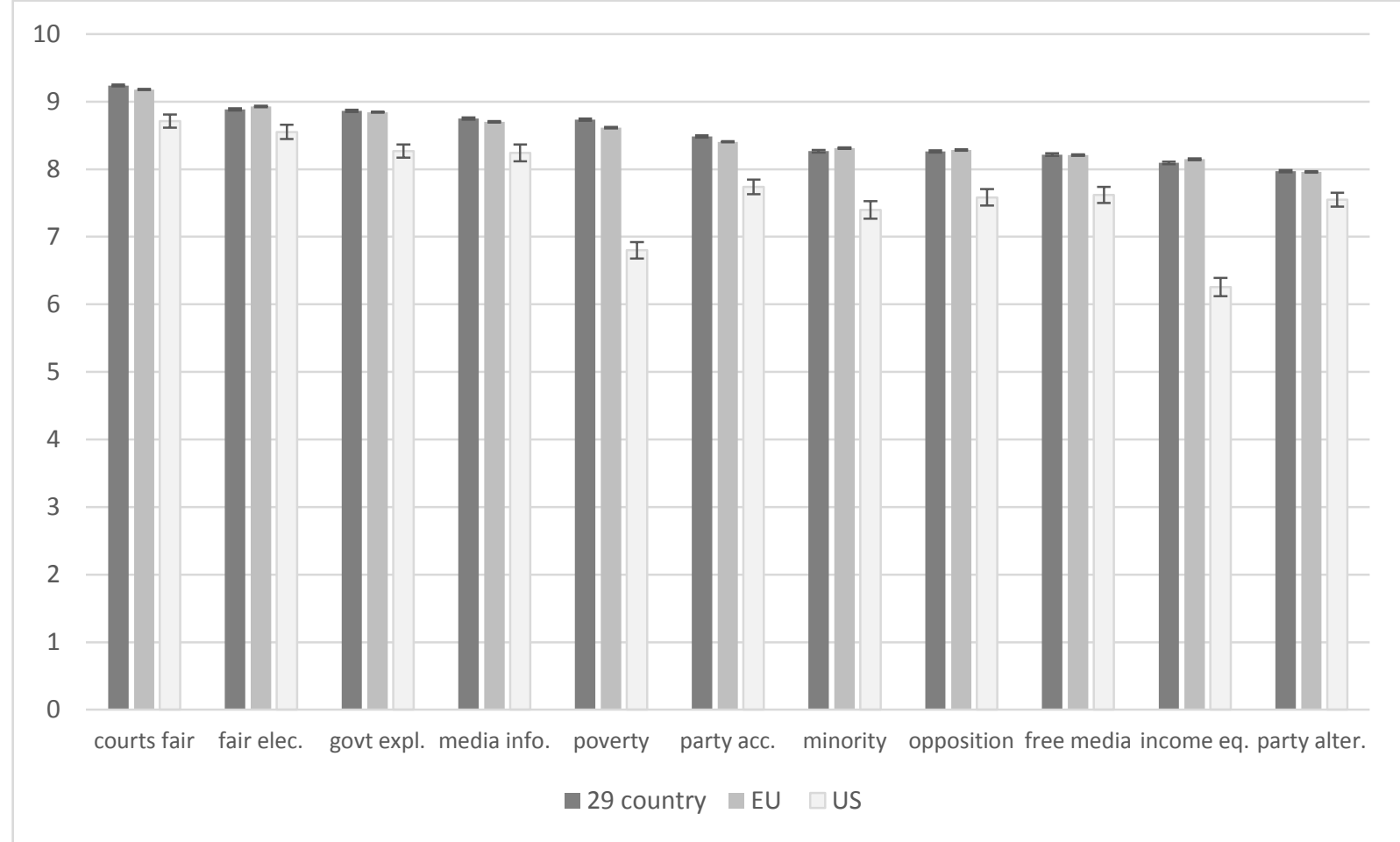

Notes: See Table 1 in manuscript for sources, sample size and methodology. Average scores for respondents of 29 ESS countries, 21 EU countries, and the United States. Whisker plots represent 95\% confidence intervals.

\section{A2. Latent class analysis and model selection}

The latent class analysis is conducted using Latent Gold software. Table A1 displays the goodness of fit statistics for selecting the optimal number of latent classes, and for testing for measurement equivalence across countries. The BIC is the most widely used statistic for assessing goodness of fit, and a smaller BIC indicates better model fit. A complementary approach is to evaluate the percent change in the likelihood chi-squared statistic $\mathrm{L}^{2}$ in comparison to the one-class model (Magidson \& Vermunt 2004: 176177). Even though the absolute value of the BIC continues to decrease through the 6class model, the percent reduction of the $\mathrm{L}^{2}$ is minimal in the 6-class model. Based on these considerations, we selected the five-class model. 
Table A1. LCA model fit statistics

\begin{tabular}{lccccc}
\hline Number classes & BIC(LL) & CAIC(LL) & L $^{2}$ & Change L & Class.Err. \\
\hline 1-Class & 1194720 & 1194742 & 414310 & & 0.00 \\
2-Class & 1020489 & 1020523 & 239949 & -0.42 & 0.04 \\
3-Class & 973207 & 973253 & 192535 & -0.54 & 0.06 \\
4-Class & 955536 & 955594 & 174733 & -0.58 & 0.08 \\
5-Class & $\mathbf{9 3 6 6 8 5}$ & $\mathbf{9 3 6 7 5 5}$ & $\mathbf{1 5 5 7 5 1}$ & $\mathbf{- 0 . 6 2}$ & $\mathbf{0 . 1 0}$ \\
6-Class & 929586 & 929668 & 148521 & -0.64 & 0.12 \\
\hline
\end{tabular}

Notes: European Social Survey, 2012 ( $n=54,673)$ merged with CCES, $2014(n=1,000)$. BIC = Bayesian Information Criterion; $\mathrm{LL}=\log$ likelihood; $\mathrm{L}^{2}=$ likelihood ratio chi-square statistics. Entries are test statistics for latent class models identifying one and more clusters of respondents, based on 11 indicators of democratic ideals with "country" as a covariate, missings imputed, and design weights applied. Optimal model highlighted in bold.

\section{A3. Latent class measurement equivalence tests}

It is important to test whether the latent classes identified in the optimal model are equivalent across the countries in the data (Kankaraš, Moors \& Vermunt, 2010; Kankaraš \& Vermunt, 2014). Table A2 includes the fit statistics of tests for two kinds of measurement equivalence:

(1) Partial equivalence means that the same latent construct (i.e., the five democratic ideals identified by the latent class analysis) is valid across all of the groups under investigation (i.e., 30 countries).

(2) Homogeneous equivalence means that the scales of the latent construct have the same origin, in addition to the same slope parameters (as indicated in partial equivalence).

The equivalence tests in Table A2 show that the partial equivalence model has the lowest BIC and is the optimal model. The subsequent models remove direct effects for single indicators to test whether full equivalence is found for specific indicators, testing first for indicators with the lowest bivariate residuals. The increased BIC in the models that selectively remove direct effects for single indicators shows that no indicators are fully homogeneous across countries, and therefore the partial equivalence model with direct effects is the optimal model. 
Table A2. Latent class analysis measurement equivalence tests

\begin{tabular}{|c|c|c|c|c|c|}
\hline Models & $\mathrm{BIC}(\mathrm{LL})$ & CAIC(LL) & $\mathrm{L}^{2}$ & Change $\mathrm{L}^{2}$ & Class.Err. \\
\hline Homogeneous model & 929450 & 929632 & 326900 & & 0.10 \\
\hline Heterogeneous model & 917778 & 919808 & 295067 & -0.10 & 0.10 \\
\hline $\begin{array}{l}\text { Partial equivalence, all } \\
\text { direct effects }\end{array}$ & 913246 & 914044 & 303976 & -0.07 & 0.11 \\
\hline $\begin{array}{l}\text { Partial equivalence, } 1 \text { direct } \\
\text { effect removed (meprinf) }\end{array}$ & 913905 & 914647 & 305245 & -0.07 & 0.10 \\
\hline $\begin{array}{l}\text { Partial equivalence, } 1 \text { direct } \\
\text { effect removed (oppcrgv) }\end{array}$ & 913885 & 914627 & 305225 & -0.07 & 0.10 \\
\hline
\end{tabular}

Notes: European Social Survey, $2012(\mathrm{n}=54,673)$ merged with CCES, $2014(\mathrm{n}=1,000)$. BIC = Bayesian Information Criterion; $\mathrm{LL}=\log$ likelihood; $\mathrm{L}^{2}=$ likelihood ratio chi-square statistics. Entries are test statistics for latent class measurement equivalence tests across countries for the 5-class model, based on 11 indicators with "country" as a covariate, missings imputed, and design weights applied. Optimal model highlighted in bold font.

\section{A4. Robustness tests}

Missing data: The reported findings include all cases in the data, including those with missing data on the questions regarding democratic ideals. We conducted two alternate analyses to ascertain the effect of missing data: (a) A listwise deletion of all cases that are missing data on any of the 11 democracy indicators (b) Retaining cases that have missing data on only one indicator in the battery, thereby analyzing $94.61 \%$ of the research population. Analyses based on these alternate codings of missing data yielded the same substantive findings.

Indicator coding: The advantage of recoding the original 11-category items into more parsimonious categories for the latent class analysis is to avoid the problem of sparse data in analyzing categorical variables (Agresti 2007). The variables in this battery are skewed toward the high end of the 11-point scale, so use of the original 11-category items creates a problem of sparse data. The 3-point recode conducted to produce the findings reported in this article recode $0-7$ to 1 ; $8-9$ to 2 ; and 10 to 3 . We also performed robustness tests to investigate whether the findings were affected by alternate codings, including: the original 11-cateory response items; dichotomous cutoffs at $6,7,8,9,10$, as well as the mean or median of each variable; an alternate 3 point coding $(0-8=1,9=2,10=3)$ and a 4 -point coding $(0-7=1,8=2,9=3,10=4)$. These tests all yielded similar substantive results as those reported in the article. 


\section{A5. Cross-national distribution of LCA groups, including confident intervals}

Table A3. Democratic ideals, distribution of citizens including Standard Errors and Confidence Intervals (addendum to Table 2 in the manuscript). [for online-appendix]

Proportion Std. Err. [95\% Conf. Interval]

Social

$\begin{array}{lllll}\text { AL } & 33.33 & 1.92 & 29.69 & 37.19 \\ \text { BE } & 18.42 & 0.90 & 16.72 & 20.25 \\ \text { BG } & 21.15 & 0.95 & 19.35 & 23.07 \\ \text { CH } & 19.41 & 1.03 & 17.47 & 21.52 \\ \text { CY } & 18.89 & 1.28 & 16.51 & 21.54 \\ \text { CZ } & 17.69 & 0.95 & 15.91 & 19.62 \\ \text { DE } & 18.54 & 0.74 & 17.13 & 20.03 \\ \text { DK } & 15.93 & 0.91 & 14.23 & 17.79 \\ \text { EE } & 17.39 & 0.78 & 15.91 & 18.98 \\ \text { ES } & 29.02 & 1.06 & 26.99 & 31.13 \\ \text { FI } & 18.92 & 0.84 & 17.33 & 20.62 \\ \text { FR } & 19.56 & 1.02 & 17.64 & 21.64 \\ \text { GB } & 19.12 & 0.93 & 17.37 & 21.01 \\ \text { HU } & 15.97 & 0.83 & 14.42 & 17.66 \\ \text { IE } & 15.93 & 0.81 & 14.41 & 17.59 \\ \text { IL } & 20.03 & 0.82 & 18.48 & 21.68 \\ \text { IS } & 15.33 & 1.37 & 12.84 & 18.21 \\ \text { IT } & 28.75 & 1.47 & 25.97 & 31.71 \\ \text { LT } & 16.52 & 0.91 & 14.81 & 18.38 \\ \text { NL } & 12.34 & 0.85 & 10.76 & 14.11 \\ \text { NO } & 17.72 & 0.95 & 15.93 & 19.66 \\ \text { PL } & 27.06 & 1.04 & 25.07 & 29.13 \\ \text { PT } & 18.03 & 0.98 & 16.19 & 20.02 \\ \text { RU } & 21.03 & 0.95 & 19.22 & 22.96 \\ \text { SE } & 13.50 & 0.80 & 12.01 & 15.14 \\ \text { SI } & 32.93 & 1.34 & 30.35 & 35.61 \\ \text { SK } & 13.76 & 1.05 & 11.84 & 15.95 \\ \text { UA } & 22.40 & 0.99 & 20.52 & 24.40 \\ \text { XK } & 20.94 & 1.44 & 18.26 & 23.91 \\ \text { US } & 14.76 & 1.66 & 11.80 & 18.33 \\ \text { TOTAL } & 19.32 & 0.18 & 18.97 & 19.68\end{array}$


Table A3 (continued)

Proportion Std. Err. [95\% Conf. Interval]

Political

$\begin{array}{lrrrr}\text { AL } & 6.87 & 1.02 & 5.12 & 9.16 \\ \text { BE } & 15.52 & 0.84 & 13.95 & 17.24 \\ \text { BG } & 18.76 & 0.90 & 17.06 & 20.58 \\ \text { CH } & 21.39 & 1.07 & 19.37 & 23.56 \\ \text { CY } & 11.64 & 1.01 & 9.80 & 13.78 \\ \text { CZ } & 17.63 & 0.98 & 15.79 & 19.64 \\ \text { DE } & 31.88 & 0.91 & 30.12 & 33.70 \\ \text { DK } & 31.00 & 1.14 & 28.81 & 33.29 \\ \text { EE } & 14.62 & 0.73 & 13.25 & 16.11 \\ \text { ES } & 6.52 & 0.57 & 5.49 & 7.73 \\ \text { FI } & 16.16 & 0.79 & 14.67 & 17.77 \\ \text { FR } & 13.51 & 0.85 & 11.92 & 15.26 \\ \text { GB } & 12.19 & 0.77 & 10.76 & 13.77 \\ \text { HU } & 11.55 & 0.72 & 10.21 & 13.03 \\ \text { IE } & 11.84 & 0.69 & 10.55 & 13.27 \\ \text { IL } & 15.77 & 0.75 & 14.36 & 17.28 \\ \text { IS } & 27.53 & 1.64 & 24.44 & 30.86 \\ \text { IT } & 10.81 & 1.01 & 8.99 & 12.94 \\ \text { LT } & 11.99 & 0.85 & 10.42 & 13.77 \\ \text { NL } & 19.38 & 1.01 & 17.47 & 21.44 \\ \text { NO } & 26.39 & 1.10 & 24.30 & 28.60 \\ \text { PL } & 16.48 & 0.86 & 14.87 & 18.23 \\ \text { PT } & 4.47 & 0.57 & 3.48 & 5.73 \\ \text { RU } & 12.39 & 0.76 & 10.97 & 13.96 \\ \text { SE } & 31.09 & 1.08 & 29.01 & 33.25 \\ \text { SI } & 10.59 & 0.88 & 8.99 & 12.44 \\ \text { SK } & 12.52 & 1.13 & 10.47 & 14.92 \\ \text { UA } & 10.80 & 0.77 & 9.37 & 12.41 \\ \text { XK } & 7.11 & 0.89 & 5.55 & 9.07 \\ \text { US } & 26.98 & 1.81 & 23.59 & 30.66 \\ \text { TOTAL } & 16.01 & 0.17 & 15.68 & 16.34\end{array}$


Table A3 (continued)

Proportion Std. Err. [95\% Conf. Interval]

High

$\begin{array}{lrrrr}\text { AL } & 46.02 & 2.03 & 42.08 & 50.01 \\ \text { BE } & 12.51 & 0.77 & 11.09 & 14.10 \\ \text { BG } & 39.50 & 1.12 & 37.34 & 41.71 \\ \text { CH } & 12.60 & 0.87 & 11.00 & 14.40 \\ \text { CY } & 41.09 & 1.62 & 37.96 & 44.30 \\ \text { CZ } & 17.46 & 0.95 & 15.69 & 19.39 \\ \text { DE } & 15.93 & 0.70 & 14.62 & 17.35 \\ \text { DK } & 16.48 & 0.92 & 14.76 & 18.36 \\ \text { EE } & 27.54 & 0.92 & 25.77 & 29.38 \\ \text { ES } & 32.02 & 1.09 & 29.93 & 34.19 \\ \text { FI } & 11.52 & 0.68 & 10.25 & 12.93 \\ \text { FR } & 17.07 & 0.95 & 15.29 & 19.02 \\ \text { GB } & 19.26 & 0.95 & 17.47 & 21.18 \\ \text { HU } & 37.92 & 1.09 & 35.80 & 40.08 \\ \text { IE } & 21.79 & 0.90 & 20.08 & 23.60 \\ \text { IL } & 23.69 & 0.87 & 22.02 & 25.43 \\ \text { IS } & 23.89 & 1.58 & 20.93 & 27.12 \\ \text { IT } & 26.23 & 1.42 & 23.54 & 29.12 \\ \text { LT } & 22.88 & 1.08 & 20.83 & 25.06 \\ \text { NL } & 9.25 & 0.72 & 7.93 & 10.76 \\ \text { NO } & 17.29 & 0.94 & 15.52 & 19.21 \\ \text { PL } & 27.16 & 1.04 & 25.18 & 29.24 \\ \text { PT } & 29.28 & 1.14 & 27.09 & 31.57 \\ \text { RU } & 26.35 & 1.02 & 24.40 & 28.41 \\ \text { SE } & 24.59 & 1.01 & 22.67 & 26.62 \\ \text { SI } & 21.27 & 1.17 & 19.07 & 23.65 \\ \text { SK } & 15.90 & 1.16 & 13.76 & 18.30 \\ \text { UA } & 31.98 & 1.12 & 29.84 & 34.21 \\ \text { XK } & 41.03 & 1.74 & 37.66 & 44.47 \\ \text { US } & 11.94 & 1.29 & 9.63 & 14.72 \\ \text { TOTAL } & 23.75 & 0.20 & 23.37 & 24.14\end{array}$


Table A3 (continued)

Proportion Std. Err. [95\% Conf. Interval]

Medium

$\begin{array}{lllll}\text { AL } & 12.90 & 1.29 & 10.57 & 15.64 \\ \text { BE } & 40.39 & 1.14 & 38.18 & 42.63 \\ \text { BG } & 16.90 & 0.85 & 15.30 & 18.62 \\ \text { CH } & 39.65 & 1.28 & 37.17 & 42.17 \\ \text { CY } & 26.18 & 1.46 & 23.43 & 29.14 \\ \text { CZ } & 30.46 & 1.17 & 28.21 & 32.80 \\ \text { DE } & 29.10 & 0.88 & 27.41 & 30.86 \\ \text { DK } & 33.88 & 1.17 & 31.63 & 36.22 \\ \text { EE } & 28.99 & 0.94 & 27.18 & 30.86 \\ \text { ES } & 25.94 & 1.02 & 23.99 & 27.99 \\ \text { FI } & 43.07 & 1.06 & 41.00 & 45.16 \\ \text { FR } & 39.48 & 1.25 & 37.06 & 41.95 \\ \text { GB } & 36.01 & 1.15 & 33.79 & 38.30 \\ \text { HU } & 21.47 & 0.92 & 19.71 & 23.33 \\ \text { IE } & 34.00 & 1.03 & 32.02 & 36.04 \\ \text { IL } & 34.41 & 0.97 & 32.53 & 36.33 \\ \text { IS } & 28.56 & 1.67 & 25.40 & 31.94 \\ \text { IT } & 29.91 & 1.48 & 27.08 & 32.89 \\ \text { LT } & 30.26 & 1.15 & 28.06 & 32.55 \\ \text { NL } & 44.72 & 1.27 & 42.24 & 47.23 \\ \text { NO } & 34.63 & 1.18 & 32.35 & 36.99 \\ \text { PL } & 25.62 & 1.02 & 23.67 & 27.66 \\ \text { PT } & 25.51 & 1.12 & 23.38 & 27.77 \\ \text { RU } & 24.03 & 1.00 & 22.13 & 26.04 \\ \text { SE } & 27.27 & 1.04 & 25.28 & 29.36 \\ \text { SI } & 29.91 & 1.31 & 27.41 & 32.53 \\ \text { SK } & 38.14 & 1.60 & 35.06 & 41.32 \\ \text { UA } & 27.52 & 1.06 & 25.50 & 29.64 \\ \text { XK } & 22.04 & 1.47 & 19.30 & 25.05 \\ \text { US } & 24.97 & 1.84 & 21.53 & 28.75 \\ \text { TOTAL } & 30.77 & 0.21 & 30.35 & 31.19\end{array}$


Table A3 (continued)

Proportion Std. Err. [95\% Conf. Interval]

Low

$\begin{array}{lrrrr}\text { AL } & 0.88 & 0.28 & 0.48 & 1.63 \\ \text { BE } & 13.16 & 0.78 & 11.70 & 14.77 \\ \text { BG } & 3.70 & 0.44 & 2.93 & 4.66 \\ \text { CH } & 6.95 & 0.66 & 5.75 & 8.37 \\ \text { CY } & 2.18 & 0.46 & 1.45 & 3.29 \\ \text { CZ } & 16.76 & 0.94 & 15.00 & 18.68 \\ \text { DE } & 4.54 & 0.40 & 3.82 & 5.40 \\ \text { DK } & 2.70 & 0.40 & 2.01 & 3.60 \\ \text { EE } & 11.47 & 0.66 & 10.24 & 12.82 \\ \text { ES } & 6.49 & 0.57 & 5.46 & 7.71 \\ \text { FI } & 10.33 & 0.65 & 9.12 & 11.68 \\ \text { FR } & 10.38 & 0.81 & 8.90 & 12.07 \\ \text { GB } & 13.42 & 0.82 & 11.89 & 15.12 \\ \text { HU } & 13.10 & 0.76 & 11.68 & 14.66 \\ \text { IE } & 16.44 & 0.80 & 14.92 & 18.07 \\ \text { IL } & 6.10 & 0.49 & 5.22 & 7.13 \\ \text { IS } & 4.69 & 0.82 & 3.33 & 6.57 \\ \text { IT } & 4.30 & 0.66 & 3.18 & 5.79 \\ \text { LT } & 18.35 & 1.00 & 16.48 & 20.40 \\ \text { NL } & 14.31 & 0.91 & 12.62 & 16.19 \\ \text { NO } & 3.97 & 0.49 & 3.12 & 5.03 \\ \text { PL } & 3.69 & 0.44 & 2.91 & 4.65 \\ \text { PT } & 22.71 & 1.05 & 20.73 & 24.82 \\ \text { RU } & 16.19 & 0.87 & 14.56 & 17.97 \\ \text { SE } & 3.55 & 0.43 & 2.79 & 4.50 \\ \text { SI } & 5.30 & 0.64 & 4.18 & 6.70 \\ \text { SK } & 19.68 & 1.21 & 17.41 & 22.16 \\ \text { UA } & 7.30 & 0.61 & 6.19 & 8.59 \\ \text { XK } & 8.88 & 1.00 & 7.10 & 11.05 \\ \text { US } & 21.34 & 1.98 & 17.73 & 25.47 \\ \text { TOTAL } & 10.15 & 0.14 & 9.87 & 10.43\end{array}$




\section{A6. Descriptive statistics and code for select analyses}

Table A4. Descriptive statistics for multilevel regression analysis

\begin{tabular}{lccccc}
\hline Variables & $\mathrm{N}$ & Mean & $\mathrm{SD}$ & Min & Max \\
\hline Individual level variables & & & & & \\
Political ideals & 55,673 & 0.163 & 0.320 & 0 & 1 \\
Social ideals & 55,673 & 0.198 & 0.348 & 0 & 1 \\
Gender (female = 1) & 55,656 & 0.544 & 0.498 & 0 & 1 \\
Age & 55,540 & 48.351 & 18.562 & 15 & 103 \\
Education & 55,309 & 1.791 & 0.771 & 1 & 3 \\
Left-right ideology & 47,358 & 3.125 & 1.234 & 1 & 5 \\
Country-level variables & & & & & \\
Democracy years & 54,921 & 48.790 & 34.060 & 0 & 94 \\
Gini coefficient & 42,106 & 0.295 & 0.041 & 0.237 & 0.379 \\
\hline
\end{tabular}

Latent class analysis code for main reported model (Latent Gold 4.5 software) model

options

algorithm

tolerance $=1 \mathrm{e}-008$ emtolerance $=0.01$ emiterations $=250$ nriterations $=50$;

startvalues

seed $=0$ sets $=10$ tolerance $=1 \mathrm{e}-005$ iterations $=50$;

bayes

categorical $=1$ variances $=1$ latent $=1$ poisson $=1$;

montecarlo

seed $=0$ replicates $=500$ tolerance $=1 \mathrm{e}-008$;

quadrature nodes $=10$;

missing includeall;

output

parameters=effect standarderrors probmeans=posterior profile bivariateresiduals;

outfile 'C:I \ESSUS_LCAoutput.sav'

id=cntry_idno

classification;

variables

samplingweight dweight rescale;

dependent cttresa_3gg, fairelc_3gg, gvexpdc_3gg, meprinf_3gg, gvctzpv_3gg,

gptpelc_3gg, rghmgpr_3gg, oppcrgv_3gg, medcrgv_3gg, grdfinc_3gg, dfprtal_3gg;

independent cntry nominal;

latent

Cluster nominal 5;

equations

Cluster <- $1+$ cntry;

cttresa_3gg <- $1 \mid$ cntry + Cluster ;

fairelc_3gg <- 1|cntry + Cluster ;

gvexpdc_3gg <- $1 \mid$ cntry + Cluster ;

meprinf_3gg <- 1|cntry + Cluster ;

gvctzpv_3gg $<-1 \mid$ cntry + Cluster ;

gptpelc_3gg <- $1 \mid$ cntry + Cluster ;

rghmgpr_3gg <- 1|cntry + Cluster ;

oppcrgv_3gg <- 1|cntry + Cluster ;

medcrgv_3gg <- 1|cntry + Cluster ;

grdfinc_3gg <- 1|cntry + Cluster ;

dfprtal_3gg <- $1 \mid$ cntry + Cluster ;

end model 


\section{Endnotes}

1. The eight countries that are surveyed in the ESS 2012 but are not members of the EU include Albania, Israel, Iceland, Norway, Russia, Switzerland, Ukraine and Kosovo.

2. In order to make a comparison between countries possible, we do not use national party identities, but a left-right self-placement scale that is used in all 30 countries. In the US sample, those that identify with the Democratic Party, on average score 2.38 on this scale, while the identifiers with the Republican Party obtain an average score of 4.05 .

3 . We also conducted parallel models of multinomial logistic regression analyses with the dependent variable of modal membership in one of the 5 latent classes. The results concur substantively with the findings presented in Tables 4 and 5. We opt to present the linear regression analysis findings that predict membership in the political ideals and social ideals groups to focus on the main theoretical relationships of interest in a way that is more readily interpretable in comparison to the multinomial regression findings. 